Article

\title{
Assessing the Geographic Expression of Urban Sustainability: A Scenario Based Approach Incorporating Spatial Multicriteria Decision Analysis
}

\author{
Walter W. Kropp and James K. Lein * \\ Department of Geography, Ohio University, Athens, OH 45701, USA; E-Mail: will.kropp@gmail.com \\ * Author to whom correspondence should be addressed; E-Mail: lein@ohio.edu; \\ Tel.: +1-740-593-1147; Fax: +1-740-593-1139.
}

Received: 15 June 2012; in revised form: 30 August 2012 / Accepted: 31 August 2012 /

Published: 20 September 2012

\begin{abstract}
Urban sustainability involves a re-examination of urban development including environmental, social and economic policies and practices that acknowledge the role of cities in global environmental change. However, sustainability remains a broadly defined concept that has been applied to mean everything from environmental protection, social cohesion, economic growth, neighborhood design, alternative energy, and green building design. To guide sustainability initiatives and assess progress toward more sustainable development patterns this construct requires a means to place this concept into a decision-centric context where change can be evaluated and the exploitation of resources, the direction of investment, the orientation of technological development, and institutional programs can be made more consistent with future as well as present needs. In this study the problem of sustainability assessment was examined and a method that couples scenario analysis with spatial multicriteria decision analysis was introduced. The integration of a spatial multicriteria decision analysis (MCDA) model for sustainable development with scenario planning resulted in an interpretation of sustainability that is more appropriate for local conditions and useful when exploring sustainability's semantic uncertainties, particularly those alternate perspectives that influence future environments.
\end{abstract}

Keywords: scenario analysis; mutlicriteria decision making; urban land use; planning 


\section{Introduction}

Sustainability has been broadly defined as a development style that satisfies the needs of current generations without compromising the ability of future definitions to meet their own needs and engendering significant environmental degradation now and into the future [1-3]. In this development context, sustainability carries the assumption that society can direct development and change toward more desirable future states by adopting policies and programs to minimize energy consumption, preserve biological diversity, reduce pollution, promote social cohesion and encourage more efficient landscape designs [4-6]. This goal-directed focus suggests that sustainable development is not a spontaneous social product, but rather a planning construct guided by policy makers and local stakeholders to ensure that unsustainable outcomes are avoided [7,8]. The challenge, however, is that sustainability is realized over a non-specific time-horizon and sufficient uncertainty exists in both definition and practice that frustrates the clear delineation between sustainable and unsustainable outcomes. Within the last decade methodologies have emerged to guide sustainability assessment and provide planning and decision-making with tools to help inform the process and clarify the uncertainties that surround the ill-structured nature of the problem. Two leading methods for assessing sustainability are the Leadership in Energy and Environmental Design (LEED) system developed by the United States Green Building Council (USGBC) and the Sustainable Sites Initiative (SSI) developed by the American Society of Landscape Architects (ASLA) [9,10]. These well known and widely applied systems provide the point of beginning to reconcile the geographic expression of urban sustainability.

Since the inception of these evaluative systems critical spatial and design factors have been identified that indicate sustainability for areas with and without development [11]. However, these current assessment tools are ill equipped to deal with the numerous, and complexly related, criteria needed to evaluate sustainable development on a broader urban scale. For example the LEED and SSI systems fail to taking into account the importance of local factors when evaluating sustainability and also cannot differentiate between high and low importance criteria [12,13]. Because sustainability can differ significantly from one geographic location to another, certain criteria may assume greater or less relevance. Additionally, these methods only rank sustainability for previously selected sites rather than the more prescriptive approach where spatial pattern of sustainability can be explored, visualized and compared; an approach that offers greater flexibility in planning and policy making arena where a selection of potential development scenarios and constraints can be examined. The research presented in this paper focuses on the use of a spatial multicriteria decision analysis (MCDA) as a means of modeling the spatial pattern of urban sustainable development under contrasting objectives. Although based on the spatial criteria adapted from the LEED and SSI rating systems, this study focus attention on the spatial pattern sustainability may assume through the addition of alternative development scenarios. By adopting this approach, research demonstrates how spatial MCDA can be used to explore alternate but plausible, future environments and provide insight regarding the spatial pattern of sustainable development under differing societal preferences. Results from this study provide a method to combine and examine the numerous, and often conflicting, spatial factors that are critical to an understanding of sustainable development. 


\section{The Spatial Dimensions of Sustainable Development}

For the purpose of this study, urban sustainability is viewed as a process, where sustainable development is not an end goal, but a progression of change in which the exploitation of resources, the direction of investment, the orientation of technological development, and institutional change are made consistent with future as well as present needs [14]. Sustainability, in this context, is therefore dynamic and open to further input, learning, and interpretation [15-18]. At present, the prevailing model of sustainable development divides the term into three dimensions, the environmental or ecological, the economic, and the social. These dimensions can each be described with spatial criteria or indicators of sustainable development [19]. For example, the LEED and SSI rating systems each evaluate sustainability based on discrete site attributes, such as land use, distance to community services, and soil type. Through the use of these criteria, a better picture of the spatial pattern of sustainable development can be gained. Based on these criteria, the LEED system proposes site selection and building design guidelines to assess sustainability. The system employs a checklist that rewards credits for each criterion met, with a combination of criteria adding up to certain levels of certification. There are currently 4 levels of certification: certified (40 to 49 credits), silver (50 to 59 credits), gold (60 to 79 credits) and platinum (80 to 100 credits) and these criteria are divided into 7 comprehensive categories:

- $\quad$ sustainable sites (1 prerequisite, 26 credits)

- water efficiency (1 prerequisite, 10 credits)

- energy and atmosphere (3 prerequisites, 35 credits)

- materials and resources (1 prerequisite, 14 credits)

- indoor environmental quality (2 prerequisites, 15 credits)

- innovation (6 credits)

- priority (4 credits)

Although building design criteria is the dominant focus, a large number of criteria indicate sustainable attributes specifically for the site-specific location. These sustainable site (SS) criteria are expressed spatially as indicators of sustainable development. For example, access to alternative means of transportation can be expressed as the distance to the nearest mass transit station, unsuitable sites, such as floodplains and important farmland, can be avoided, and more suitable sites with scenic and recreation value can be valued higher (Table 1).

The Sustainable Sites Initiative (SSI) introduces site selection guidelines to aid in sustainable development that are intended to supplement those adopted by the USGBC's LEED system [10]. The SSI system centers on a set of design prerequisites and site criteria that must be met in order for a given location to qualify as sustainable. The criteria are divided into 7 comprehensive categories:

- $\quad$ site selection (3 prerequisites, 1 credit)

- pre-design assessment and planning (3 prerequisites, 1 credit)

- $\quad$ site-design ecological components (4 prerequisites, 16 credits)

- $\quad$ site-design human health components (11 credits)

- $\quad$ site-design materials selection (1 prerequisite, 8 credits)

- construction (2 prerequisites, 4 credits) 
- operations and maintenance (1 prerequisite, 4 credits)

The SSI criteria add more local indicators of sustainability, focusing not only on building sustainability but also on landscapes where no structures need to be built. Additionally, credits are awarded to social interaction areas, such as farmers' markets, performance centers, fairs, and concert halls [10]. Broad criteria such as these expand LEED's narrow view of sustainable criteria to include more aspects of human health and well being, however, criticism surrounding systems focuses on their "one-size fits all" checklist style approach which imposes rigidity and frustrates differentiation between high and low importance criteria [20].

Table 1. Leadership for Energy and Environmental Design Sustainable Sites Criteria.

\begin{tabular}{ll}
\hline Credit & Description \\
\hline Prerequisite 1 & Pollution Prevention \\
\hline Credit 1 & Site Selection \\
\hline Credit 2 & $\begin{array}{l}\text { Developmental Density and Community } \\
\text { Connectivity }\end{array}$ \\
\hline Credit 3 & Brownfield Redevelopment \\
\hline Credit 4.1 & Alternative Transportation-Public \\
& Transportation Access \\
\hline Credit 4.2 & Alternative Transportation-Bicycle Storage \\
\hline Credit 4.3 & Alternative Transportation-Low Emitting \\
\hline Credit 4.4 & Vehicles \\
\hline Credit 5.1 & Alternative Transportation-Parking Capacity \\
\hline Credit 5.2 & Site Development - Protect or Restore Habitat \\
\hline Credit 6.1 & Sire Development - Maximize Open Space \\
\hline Credit 6.2 & Stormwater Design - Quantity Control \\
\hline Credit 7.1 & Stormwater Design - Quality Control \\
\hline Credit 7.2 & Heat Island Effect - Non roof \\
\hline Credit 8 & Heat Island Effect - Roof \\
\hline
\end{tabular}

Ideally, sustainability assessment should allow for place-specific criteria to be incorporated, enable the application of importance weights to emphasize the criteria's meaning in the evaluation of sustainable development and provide an opportunity for large groups of people to come together and discuss how they define and think of sustainability. This public participation process utilizes sustainability's broad appeal to build a consensus and arrive at an agreed-upon assessment that reflects the views and concerns of the area's residents and stakeholders [21-23]. With enhanced public participation, sustainability assessment is more understandable to its audience, more practical for policy makers, and more relevant to local residents and issues. Multicriteria decision making (MCDM) provides a robust system that can deal with many weighted criteria and can serve as a vehicle to guide the interaction between policy makers and public participants. 


\section{Multicriteria Sustainability Assessment}

Multicriteria decision making (MCDM) is mechanism to assist the decision maker in selecting the satisfying alternative from a number of feasible alternatives under the presence of multiple choice criteria and priorities [24]. Typically, the MCDM technique begins with the generation of discrete set of alternatives, the formulation of the set of criteria, and the evaluation of the impact of each alternative on every criterion [24,25]. The input criteria are organized in a decision matrix where the rows of the matrix represent the alternatives; each attribute and the cells of the matrix contain the measured or assessed values of attributes with respect to the alternatives [26,27].

Generally, MCDM models involve 6 components:

1. The goal or goals that the decision maker hopes to achieve

2. The decision maker along with their preferences with respect to evaluation criteria

3. A set of evaluation criteria (objectives and attributes) on which the decision maker evaluates alternative courses of action

4. The set of decision alternatives

5. The set of uncontrollable variables or states of nature

6. The set of outcomes associated with each alternative

When the criteria involved are inherently geographic in nature; a variant of MCDA model; referred to as Spatial MCDA, can be applied. This decision analysis approach directs attention to the problem of choice among alternatives where choice involves a set of geographically defined alternatives, defined by sets of geographically defined attributes. According to this methodology the most critical aspect of decision problem concerns an evaluation based on the geography of attribute values and the decision maker's preferences with respect to those attribute values. The decision maker defines the decision problem, sets the goal, chooses the evaluation attributes, and decides importance weights to those the attributes.

Spatial MCDA develops around three phases [26]: (1) an intelligence phase which takes place inside a Geographic Information System (GIS) and requires careful identification and selection of all the relevant influencing and constraining factors of the problems; (2) a design phase which incorporates the decision maker's preferences and identifies the set of feasible alternatives, and (3) the choice phase which applies the decision rules and performs a sensitivity analysis in order produce a final recommendation. Although each phase uses both GIS and MCDM methodologies the phases differ in the degree to which each methodology is used. Owing to the geographic nature of the decision problem GIS techniques play a larger role in the early stages of an assessment which then give way to MCDM techniques as analysis moves toward a final decision. Resolving a decision problem using Spatial MCDA requires [26,27]:

Problem Definition. This step necessitates broadly defining the gap between the desired and existing states as defined by the decision maker. This involves setting the decision environment, obtaining and processing raw data, and examining that data for any problems. 
Evaluation Criteria. In spatial MCDA, each criterion is represented inside a geographic information system as a map layer. This specifically involves the set of attributes, which measure progress towards the objective, and the set of constraints, which are used to remove areas characterized by unwanted attributes and/or values of attributes.

Alternatives. The evaluation of criteria and constraints create a set of outcomes termed alternatives. These states of environment are created through comparison among standardized criteria via an aggregation function.

Criterion Weights. The decision maker expresses the relative importance of criteria in terms of numbers, often called criterion weights. The result is a criterion map that represents the combination of decision maker's preferences and attribute values.

Decision Rules. This step brings together the results of the preceding three steps. A decision rule or aggregation function is used to integrate geographic data layers and criterion weights to provide an overall assessment of alternatives.

Sensitivity Analysis. The analysis determines how the outcome is influenced by changes in the model structure, input criteria, and weights. It is often viewed as an exploratory process to gain a better understanding to the structure of the problem, and to learn how the various decision elements interact.

Recommendation. The end result of the decision-making process is a recommendation for future action based on the ranking of alternatives in sensitivity analysis. Visualization techniques are often used to communicate the recommendation in geographic space.

\subsection{Scenario Specification}

The ultimate goal of conceptualizing, evaluating, and measuring sustainable development has always been to improve the planning process and bring about a more sustainable world. With this objective in mind, several plausible planning scenarios were designed and tested using the Spatial MCDA model for sustainable development. The scenarios themselves are constructed as stories that describe current and future environmental states. These stories paint the broad strokes of most important issues to the decision maker. Through the inclusion and weighting of factors in the spatial MCDA model, the decision maker constructs the scenario around his or her preferences. Scenario analysis stresses thinking deeply and creatively about the future, so as to not be surprised or unprepared, and planning for multiple plausible future scenarios [28]. The process provides an opportunity to achieve various planning objectives, gather intelligence, stimulate imagination, and encourage visionary action [29]. In the context of sustainability assessment, scenario analysis enables communities to understand the future trends and the interplay between alternatives, prioritize and develop strategies to craft the desirable future outcome [29]. Six sustainability scenarios were developed and analyzed with the spatial MCDA model. 
Scenario 1: Equal Factor Weighting: The scenario represents the view that all factors of sustainable development should be treated as equally important. The treatment of factors as identical in significance when evaluating sustainable development relates directly to the 3-pillarmodel of sustainable development: sustainable development is only possible where all factors are taken into account and treated equally. The decision maker's preferences treat criteria such as mass-transit access, recreation, community connectivity, social interaction, habitat protection, historical sites, and brownfields as equally important. This all-purpose scenario for sustainable development does not emphasize one factor over another; rather it should be viewed as a baseline scenario that does not take into account any special preferences of the decision maker or planner.

Scenario 2: Equal Weights without Social Interaction: The second scenario represents the view that all criteria of sustainable development should be treated as equally important, however it removes the factor of social interaction from the model. This scenario describes the preferences of the decision maker who does not value the social interaction criteria or simply does not have the ability or data access to adequately account for that factor. The remaining criteria of mass-transit access, recreation, community connectivity, habitat protection, historical sites, and brownfields are treated as equally important in the decision maker's preferences.

Scenario 3: Emphasizing Mass-Transit Access: The third scenario represents the situation where the decision maker values the mass transportation factor above the remaining factors. This value scheme goes against the dominant model of sustainable development where all criteria are treated as equal. The decision maker's preference to emphasize the mass-transit access factor describes a world state that is more concerned with issues involving sustainable transportation options. The other factors of recreation, community connectivity, social interaction, habitat protection, historical sites, and brownfields are not forgotten; they are simply given lower importance weights. This situation could arise where pressure is placed on development to consider the most efficient and environmentally friendly options for transportation.

Scenario 4: Emphasizing Mass-Transit Access without Social Interaction: The fourth scenario represents the situation where the decision maker values mass-transportation access above all other factors, while also eliminating the value of social interaction. Like models two and three, this model goes against the dominant view of sustainable development that treats all factors as equal. The decision maker's preferences describe a world state where transportation issues are paramount, and social interaction is irrelevant.

Scenario 5: Emphasizing Habitat Protection: The fifth scenario represents the situation where the decision maker values habitat protection over all other factors. This scenario would characterize development in a very bio-diverse region where even relatively small disruptions in habitat could have very large effects on the larger environment. The remaining factors of mass-transit access, recreation, community connectivity, social interaction, historical sites, and brownfields are still taken into account, but rank lower in importance compared to the habitat protection factor. 
Scenario 6: Emphasizing Habitat Protection without Social Interaction: The sixth scenario represents the situation where the decision maker values the habitat protection above all other factors, while also eliminating the value of the social interaction factor. The decision maker's preferences describe a world state where habitat protection is vital, and social interaction is irrelevant. An example of this scenario would characterize a development similar to the one in scenario 5; yet the planner is willing to sacrifice more to ensure habitat protection. This scenario removes any influence from the social interaction factor while emphasizing the habitat protection factor.

\subsection{Scenario Analysis with Spatial MCDA}

Several approaches to sustainability assessment have been introduced [30]. The methodology applied in this study which focused on sustainability in the spatial domain required five discrete steps: 1. problem assessment; 2. Data collection and preprocessing; 3. Specification of influences and constraints; 4. model development; 5. evaluation (Figure 1).

Figure 1. Spatial Sustainability Assessment Methodology.

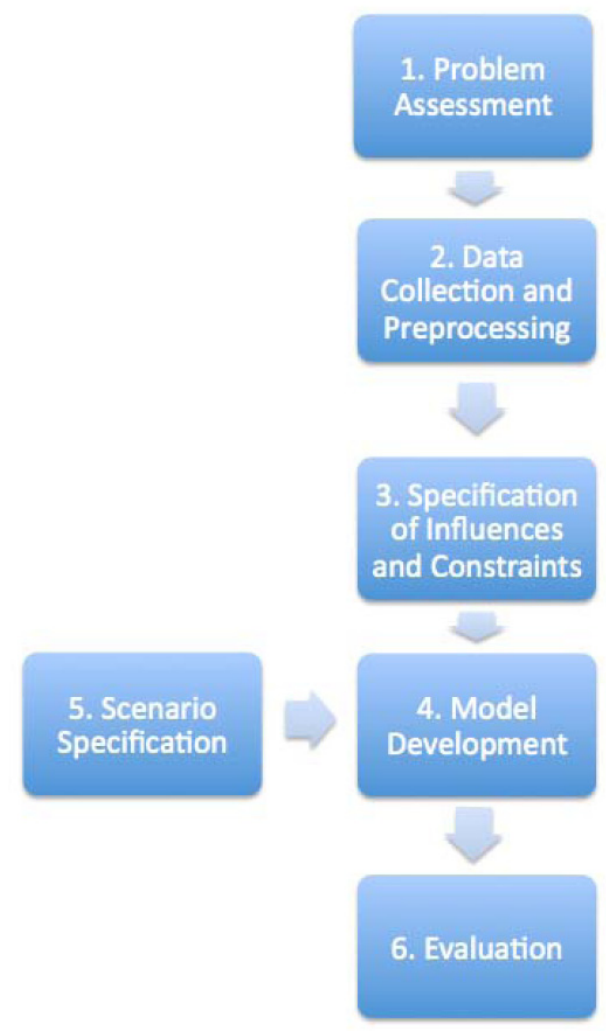

- Problem Assessment: To begin modeling sustainable development, factors that influence and constraint the potential patter where assembled in raster representations for GIS analysis. The factors for sustainable development were adapted from the criteria listed by the SSI and the LEED 3.0 for New Construction. Data layers representing each constraint and influence were created in ArcGIS from data acquired from MassGIS data files. Factors including prime farmland, floodplain, endangered species habitat, wetlands, waterbodies, and parkland were considered constraining factors. These factors limit and 
remove any possibility of development on a piece of land. Other factors that are considered in the sustainable development model are those that influence the spatial distribution of sustainable land. These factors included mass-transit access, recreation, community connectivity, social interaction, habitat protection, historical sites, and brownfields. Subjective weights were assigned to each layer based on their relative importance in the sustainable development model and then combined using the raster calculator function within the ArcMap software application. Ideally, factor weights can be acquired through public participation and other mechanisms to gain insight regarding local community preferences. Given the demonstration nature of this study, weights were developed using an ad hoc solution designed specifically for this study as are therefore, non-generalizable, and not intended to be adapted to other purposes.

- Data Collection and Preprocessing: The second step in the process involved collecting the relevant data, converting to the appropriate file formats, and standardizing files into the appropriate spatial extent and cell size. All relevant data were imported into ArcMap and assigned one consistent projection, extent, and cell size. The shapefiles were converted into grid raster format using a cell-size of $10 \times 10 \mathrm{~m}$. All files were given the projection: NAD 1983.

- Influences and Constraints: Following data collection and preprocessing, data layers representing each constraint and influence were created in ArcGIS. A brief description of each is provided in Table 2 and Table 3. Constraining factors limit and remove any possibility of development on a parcel of land, while influencing factors direct the spatial pattern of sustainable development.

- Model Development: The municipality level of scale was chosen for analysis due to the nature of the spatial criteria provided by the LEED and SSI systems. A municipality-sized area encompasses the community level criteria and also provides an appropriate scale to investigate land use and zoning in relation to the spatial pattern of sustainable development. The influencing factors of mass-transit access recreation community connectivity, social interaction, habitat protection, historical sites, and brownfields were converted into distance grid rasters from their original format. The Euclidean distance was used to calculate the distance from these sites for each raster cell. The Simple Additive Weighting (SAW) method, also known as Weighted Linear Combination (WLC) or scoring methods, was used to design the model. This method is based on the weighted average, where an evaluation score is calculated for each alternative by multiplying the importance weight assigned for each attribute by the scaled value given to that alternative on that attribute, followed by a summing of the products for all criteria. This technique was chosen for its easy implementation within a GIS using map algebra operations and transparency in aiding decision making. The standardized rasters were then weighted and combined using the raster calculator. The simple additive function multiplies each distance raster by a weight and then adds together the resulting layers. Weights represent the percent influence in the evaluation model and can range from 0 (no influence) to 1 (total influence) with all weights summing to 1 . The specific weights for each data layer in every model are shown in Table 4.. 
- Evaluation: The output data layers generated via GIS Spatial MCDA described from the pattern of sustainable development as a series one continuous surfaces for each scenario evaluated. For visualization purposes the model output layers were classified using a quantile classification scheme to simplify interpretation. The data layers representing the constraining factors were then overlain above the influencing factors in the analysis phase to represent areas that could be considered unsustainable locations. Through the analysis of these patterns in concert with current land use and zoning regulations, a deeper understanding can be gained of sustainable development's spatial expression, and comparisons between scenarios can serve to inform future planning decisions.

Table 2. Constraining Factors for Spatial Multicriteria Decision Analysis (MCDA)

\begin{tabular}{ll}
\hline Factor & Description \\
\hline Prime Farmland & $\begin{array}{l}\text { Soils designated by USDA Natural Resource Conservation } \\
\text { Service as prime farmland unique soils or soils of statewide } \\
\text { importance }\end{array}$ \\
\hline Floodplain Avoidance & $\begin{array}{l}\text { Defining the baseline setback width of the 100-year } \\
\text { floodplain surrounding streams and lakes of any size as } \\
\text { defined by the Federal Emergency Management Agency } \\
\text { (FEMA) }\end{array}$ \\
\hline Endangered Species & $\begin{array}{l}\text { Land specified as habitat for any state or federally listed } \\
\text { threatened or endangered species }\end{array}$ \\
\hline Wetlands & $\begin{array}{l}\text { Defined by 100-foot buffer around wetlands to protect the } \\
\text { wetland from human disturbance }\end{array}$ \\
\hline Waterbodies & $\begin{array}{l}\text { Defined as seas, lakes, streams, ponds, or any body of } \\
\text { water that can support fish, recreation or industrial use }\end{array}$ \\
\hline Parkland & $\begin{array}{l}\text { Land use supporting recreational opportunities described } \\
\text { by conservation and outdoor recreational facilities }\end{array}$ \\
\hline
\end{tabular}

Table 3. Influencing Factors for Spatial MCDA.

\begin{tabular}{ll}
\hline Factor & Description \\
\hline $\begin{array}{l}\text { Access to public mass } \\
\text { transit }\end{array}$ & $\begin{array}{l}\text { Public mass transit systems such as rail. bus and carpool } \\
\text { options }\end{array}$ \\
\hline Outdoor recreation & $\begin{array}{l}\text { Recreational open space sites and trails providing areas for } \\
\text { physical activity and mental restoration }\end{array}$ \\
\hline $\begin{array}{l}\text { Community } \\
\text { connectivity }\end{array}$ & $\begin{array}{l}\text { Services such as banks, libraries, health centers, police and } \\
\text { fire stations and museums that channel growth within } \\
\text { existing infrastructure }\end{array}$ \\
\hline Social interaction & $\begin{array}{l}\text { Areas defined as gathering places that allow small to large } \\
\text { groups to congregate for the purpose of building } \\
\text { community and improving social ties such as performance } \\
\text { centers, museums, farmers markets, concert halls }\end{array}$ \\
\hline Habitat protection & $\begin{array}{l}\text { Locations identified as areas most in need of protection by } \\
\text { the Natural Heritage Program (NHESP) }\end{array}$ \\
\hline Historic sites & $\begin{array}{l}\text { Sites with a historical or cultural primary purpose such as } \\
\text { historic cemeteries, battlefields and historical parks. }\end{array}$ \\
\hline Brownfields & $\begin{array}{l}\text { Any land use that may be complicated by the presence of a } \\
\text { hazardous substance, pollutant or contaminant. }\end{array}$ \\
\hline
\end{tabular}


Table 4. Factor Weighting Schema for Each Scenario.

\begin{tabular}{lcccccc}
\hline \multicolumn{1}{c}{ Factors } & $\mathbf{1}$ & $\mathbf{2}$ & $\mathbf{3}$ & $\mathbf{4}$ & $\mathbf{5}$ & $\mathbf{6}$ \\
\hline Mass-Transit Access & 0.1428 & 0.166 & 0.250 & 0.2856 & 0.125 & 0.1428 \\
\hline Recreation & 0.1428 & 0.166 & 0.125 & 0.1428 & 0.125 & 0.1428 \\
\hline Community Connectivity & 0.1428 & 0.166 & 0.125 & 0.1428 & 0.125 & 0.1428 \\
\hline Social Interaction & 0.1428 & 0.000 & 0.125 & 0.000 & 0.125 & 0.000 \\
\hline Habitat Protection & 0.1428 & 0.166 & 0.125 & 0.1428 & 0.250 & 0.2856 \\
\hline Historical Sites & 0.1428 & 0.166 & 0.125 & 0.1428 & 0.125 & 0.1428 \\
\hline Brownfields & 0.1428 & 0.166 & 0.125 & 0.1428 & 0.125 & 0.1428 \\
\hline
\end{tabular}

\section{Scenario Assessment}

This project set out to represent and analyze the spatial pattern of sustainable development in using the municipality of Becket Massachusetts as the study site. The municipality of Becket lies in the Berkshire Hills of southwestern Massachusetts, 118 miles west of Boston. This predominantly rural environment has a population of approximately 1800 residents. Land cover of the region is primarily forested (83\%) with residential development (7\%) and water/wetlands (5\%) comprising the main land cover features (Figure 2). The constraints established based on land use and environmental considerations is presented in Figure 3.

Urban pattern is centered in the three village centers of North Becket, Becket Center, and West Becket with the following developmental characteristics as identified by the Becket Open Space Planning Committee [31]:

- Transportation. Becket is rather unconnected concerning transportation. There are no mass transit options for the municipality. The Massachusetts Turnpike does run through the area, however there is no exit in Becket. The two principle routes into and out of Becket are Routes 8 and 20.

- Natural Resources. Becket is rich in natural and scenic resources. The municipality includes the headwaters of three watersheds: the Housatonic, Farmington, and Westfield River watersheds along with numerous scattered throughout wetlands. Becket's forested lands and water resources provide habitat for a number of rare and endangered plant and animal species including the wood turtle and great blue heron.

- Cultural Resources. Becket contains unique scenic, cultural, and historic areas. The West Branch of the Westfield River, one of the largest roadless areas in the State, has been classified as a Wild and Scenic River. The North Becket Village has been designated a National Historic District. Also, Becket is home to Jacob's Pillow Dance Festival, which is known as America's first and longest running dance festival.

- Threats. Becket's main environmental threats come from development. "The intense development that has historically occurred around some of Becket's lakes has diminished their use for wildlife". Development introduces new sources of nonpoint pollution, and invasive aquatic species to the area along with removing trees and other shoreline vegetation. 
Figure 2. General Land Cover for Becket Massachusetts; 2010.

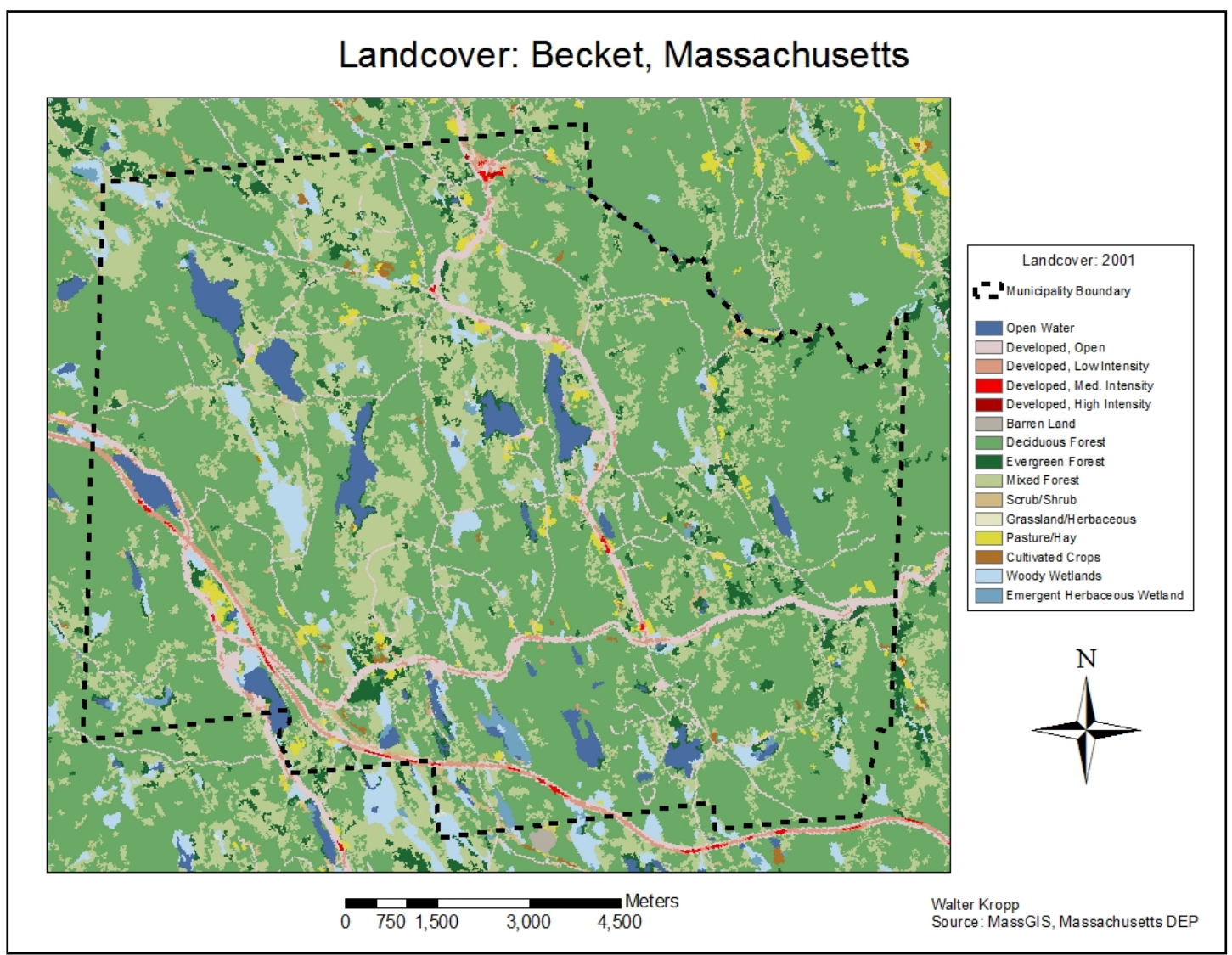

Figure 3. Areas of Land Use and Environmental Constraint for Becket Massachusetts; 2010.

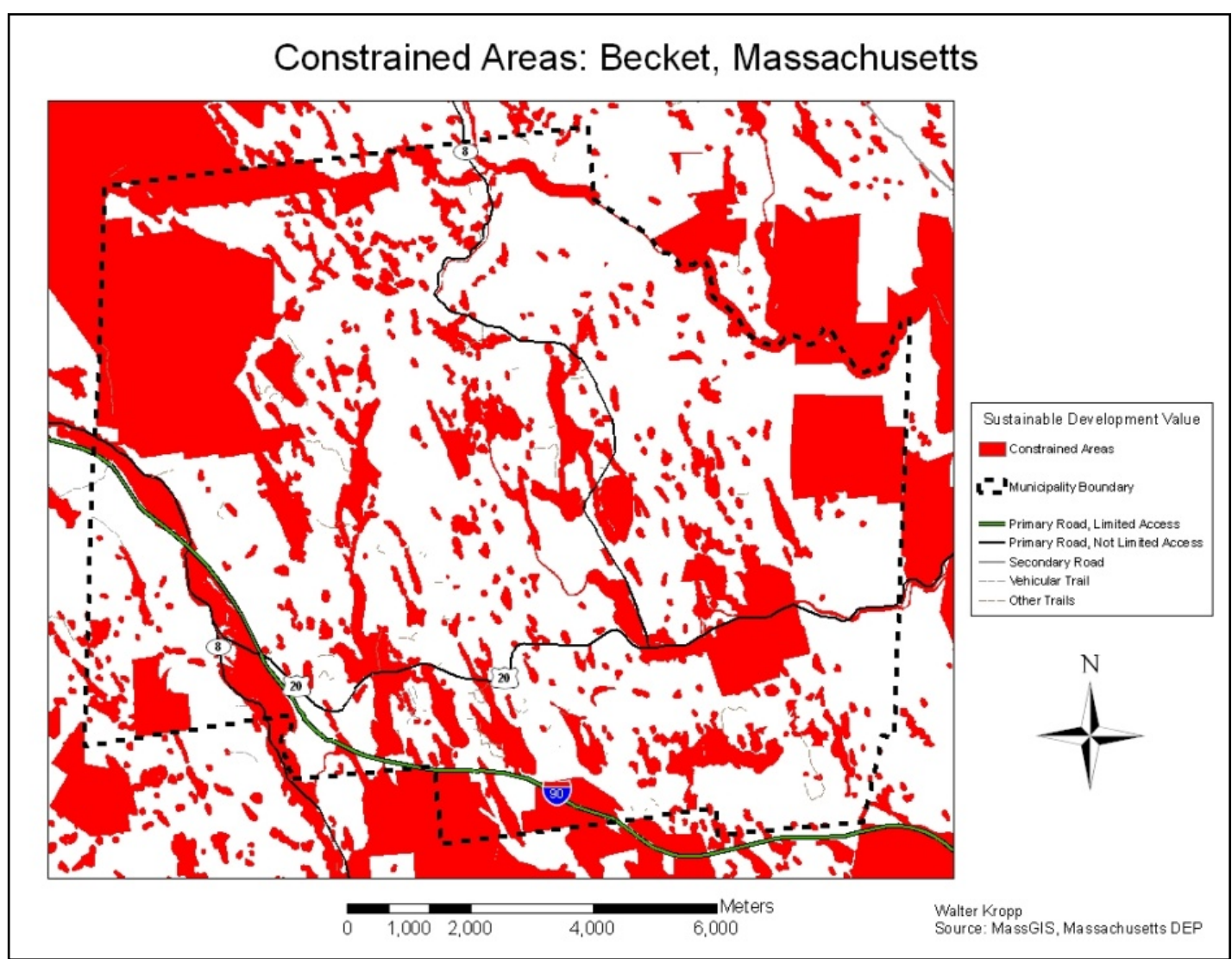


The six scenarios discussed previously were examined for the Becket study site. A selection of those are reported here to demonstrate the application of Spatial MCDA in sustainability assessment and the manner by which subjective judgment can be employed in the analysis produce a robust evaluation that is sensitive to the complexities that underscore the concept of sustainability.

- Scenario 1: Equal Weights: The assumptions expressed under this scenario represent the dominant view that factors of sustainable development should be treated with equal importance (Figure 4). Comparing the results of this model run with others will also help determine how changes in the input factors and weights influence the pattern of sustainable development. For the Becket example higher values for sustainable development were assigned to areas in the northeastern corner of the municipality running along Route 8 . This area of Becket contains most of its business and services including the Ambulance Department and historic district. The largest constrained areas are in the northwestern corner of the municipality (October Mountain State Forest) and the eastern edge near Route 20 (Becket State Forest, and Conservation Land).

Figure 4. The spatial pattern of Scenario 1 for Becket, Massachusetts with Constraints.

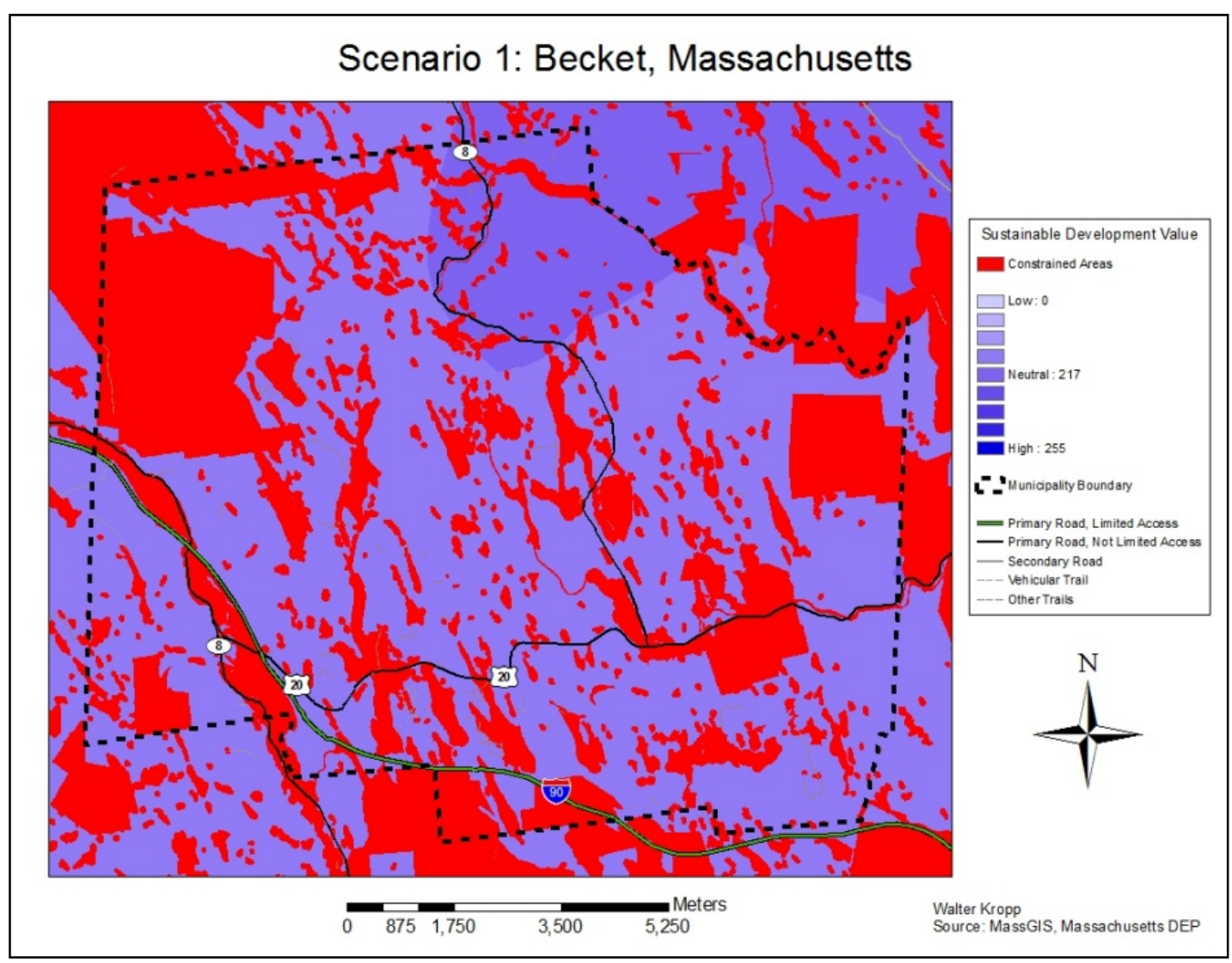


- Scenario 2: Equal Weights without Social Interaction: This example characterizes the scenario where social interaction information is simply not available or is viewed as unimportant. For the Becket study area the pattern of sustainable development assigned higher values to most of the northern portion of the municipality and lower values to the southern portion (Figure 5). The largest constrained sections in the areas with high sustainable development values were the October Mountain and Becket State Forests. Areas near the interstate highway (I-90); which includes a large housing development, were classified as less suitable for sustainable development.

Figure 5. The spatial pattern of Scenario 2 for Becket, Massachusetts with Constraints.

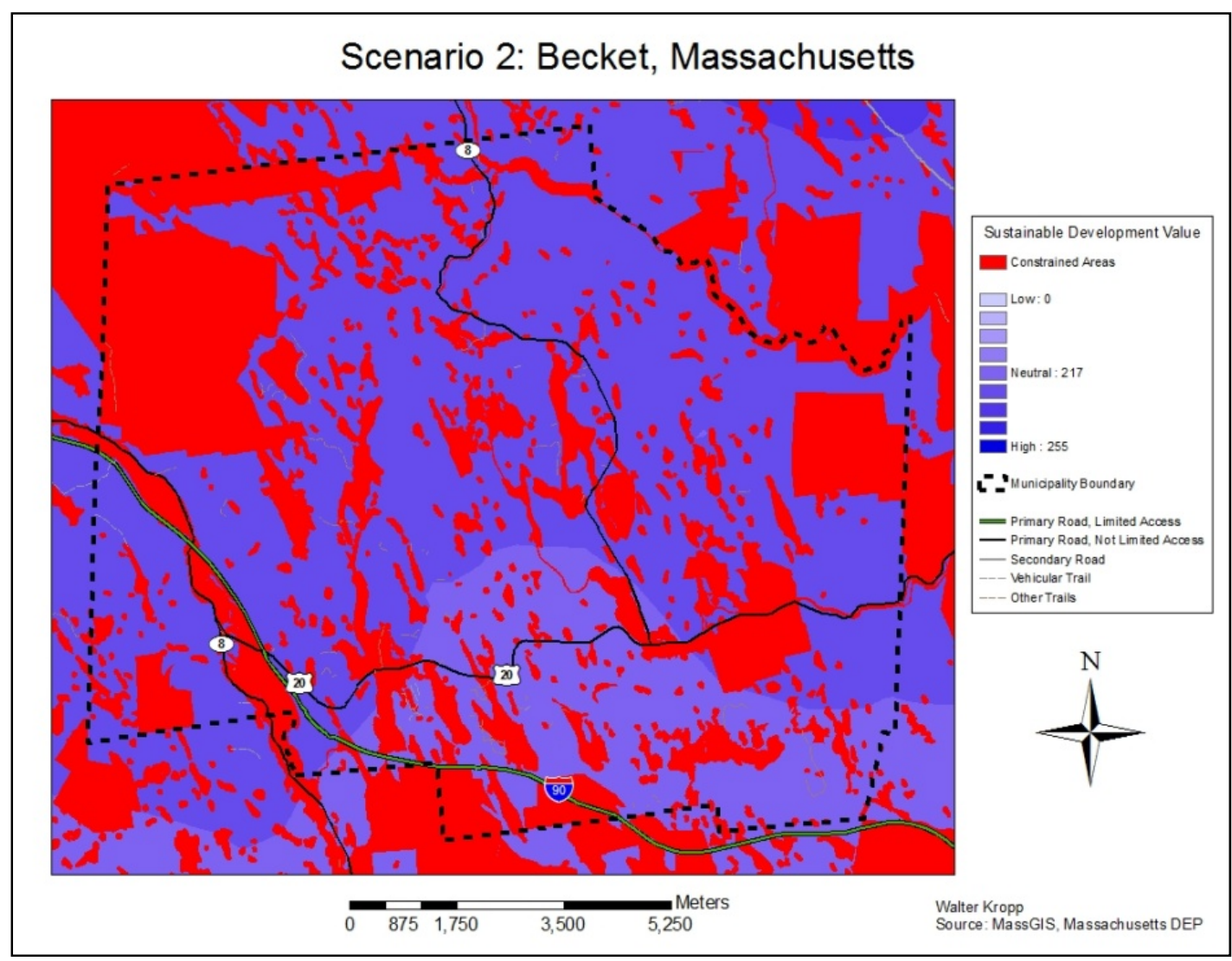

- Scenario 4: Emphasizing Mass-Transit Access without Social Interaction: This scenario emphasizes that desire for development to occur near mass transit access, where traffic and emissions can be reduced (Figure 6). However, this scenario also removes the social interaction factor that highly values outer meeting places used to build community and improve social ties. For the study area this scenario produced the highest values for sustainable development in the northeastern corner of the municipality. Sustainability score declined from north to south.

- Scenario 6: Emphasizing Habitat Protection without Social Interaction: This scenario combines the desire to preserve habitat with the decision not to value social interaction (Figure 7). For the case study site higher sustainability scores were assigned to areas in north Becket along Route 8 and extending into central Becket. 
Figure 6. The spatial pattern of Scenario 4 for Becket, Massachusetts with Constraints.

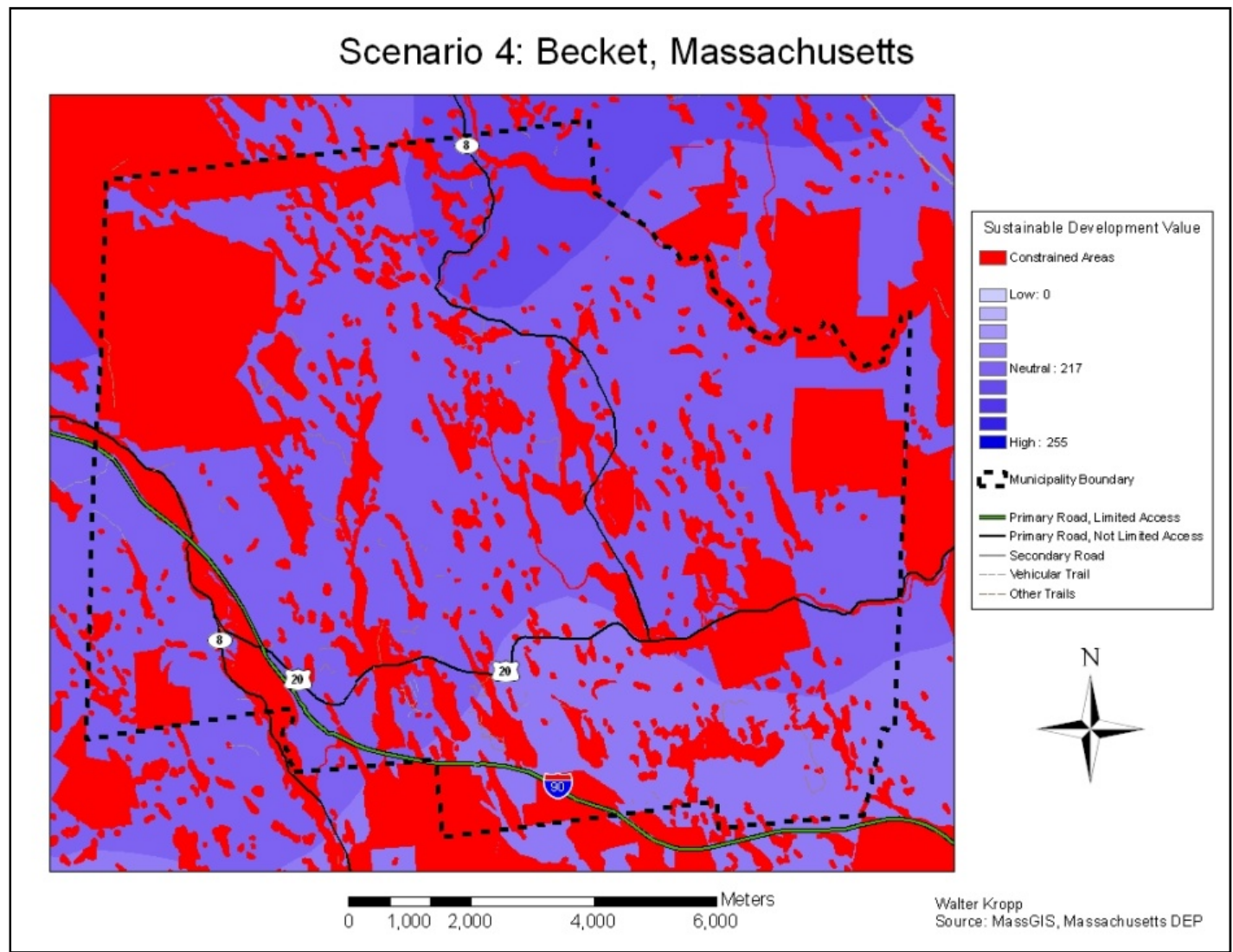

Figure 7. The spatial pattern of Scenario 6 for Becket, Massachusetts with Constraints.

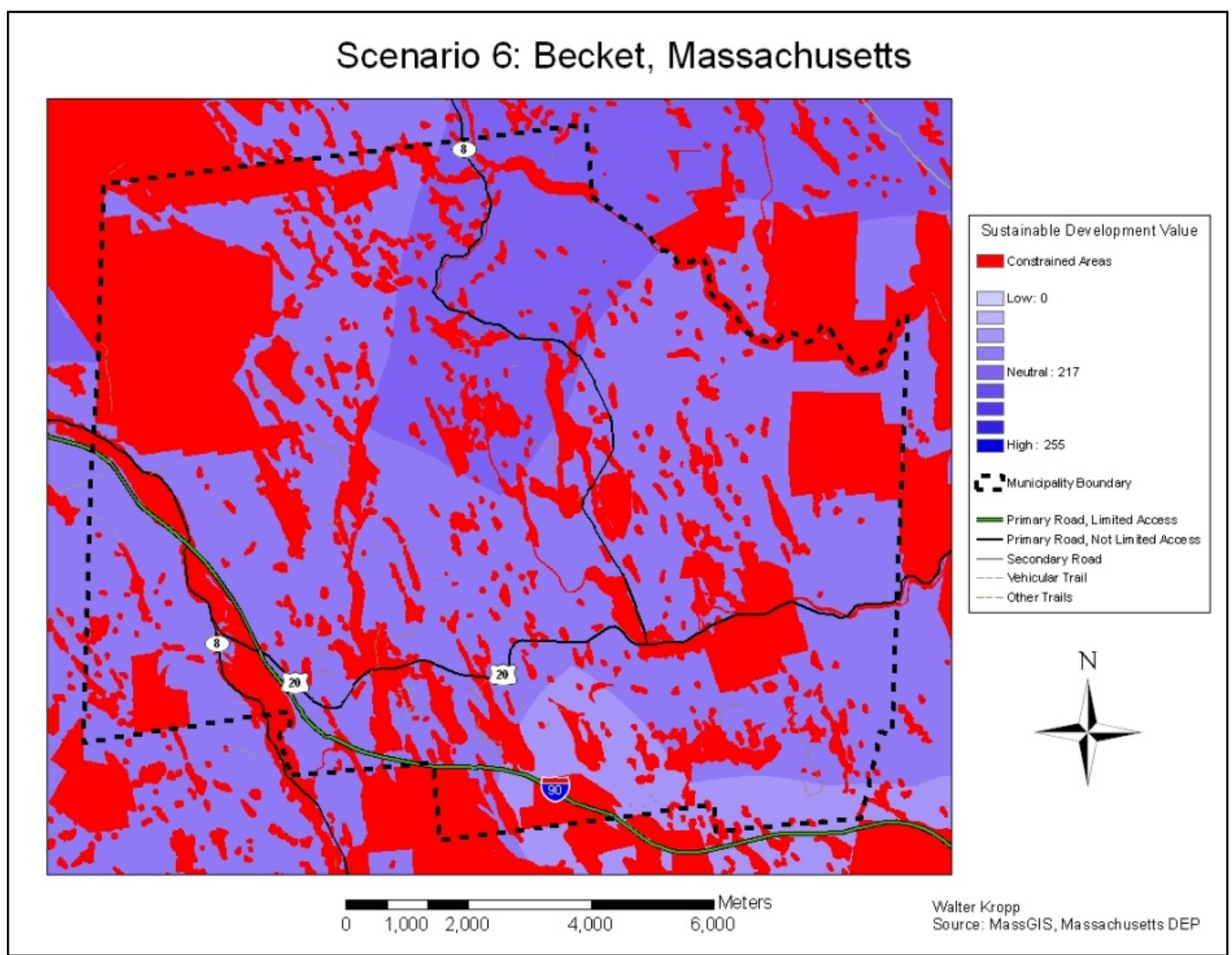




\section{Conclusions}

In order for sustainable development to be managed, it must first be measured and evaluated. Systems such as LEED and SSI cannot handle the complexity of the factors that contribute to sustainable development and suggest avenues to develop new and more flexible approaches. Spatial Multi Criteria Decision Analysis introduced in this paper facilitated detailed examination of several plausible planning scenarios that could influence the pattern of sustainable development. Although there is no absolute "best" result, the spatial expression of sustainability over the study area produced from this analysis enhances the visualization of the various "trade-offs" that options that influence policy making. For the Becket example, alternatives that included or excluded the social interaction factor evidenced the greatest variation in sustainability. Here, the removal of social interaction compressed the pattern and reduced the area that could be considered sustainable for future use. In contrast, scenarios that did not include social interaction produced higher values particularly in north Becket along the Route 8 corridor. This portion of the study site is the heaviest developed area and is home to the North Becket historic district, Becket Land Trust, Becket schools, and Ambulance Department. The higher sustainability score related to the presence of essential services, historic districts, and mass transit access. The scenarios emphasizing mass-transit access and emphasizing habitat protection also produced higher sustainable development scores in the area of north Becket. However areas to the south that lack mass-transit options and essential services were categorized as less sustainable. Overall, when emphasizing one factor over others, the results acted to restrict the amount of land area suitable for sustainable development. The narrowing of the preferences of the decision maker produced in a narrowing of areas suitable for sustainable development. This outcome proves useful in a scenario planning analysis when exploring future environments and the potential impact of one alternative over others. In this context, the contrasting influences that direct sustainable development offer decision makers with differing views that will produce differing spatial outcomes.

The Spatial Multicriteria Decision Analysis (MCDA) methodology employed in this study was based on well established criteria for guiding sustainable development programs, and through its capacity to enable ranking, weighting, and combining decision criteria, unique insight pertaining to: (1) the locations where future development could be considered more sustainable; (2) the role of criteria selection and preference in modifying the geographic pattern of sustainable development, and (3) the utility of Spatial MCDA in scenario planning and assessment could be realized. As demonstrated for the Becket, Massachusetts example, the spatial representation of sustainable development transformed the concept into a tangible entity, while the process of selecting and describing criteria, choosing preference weights, and evaluating the results in a spatial context acted to clarify the components that impact sustainability as an active feature of the urban landscape. Furthermore, the adaptability of this approach offers a flexible and effective methodology to explore and evaluate the spatial pattern of sustainable development elsewhere. In this role, Spatial MCDA becomes a prescriptive tool, useful in guiding the visualization of sustainable development and informing the planning of future urban development in a consistent and coherent manner. While the practical problems related to definition and measurement conspire to frustrate simple estimation of sustainability, the concept remains useful in three respects: 
- Raising question about development strategies

- Providing insight regarding the relationship between human activities and environmental degradation

- Assisting in setting priorities in response to growth pressures.

The flexibility of the Spatial MCDA approach provides the opportunity to employ differing metrics utilizing contrasting criteria over the fabric of the landscape, and encourages the assessment of each land type on its own merits and how each contributes to overall sustainability and finer spatial scales.

\section{Conflict of Interest}

The authors declare no conflict of interest.

\section{References}

1. Mebratu, D. Sustainability and sustainable development: Historical and conceptual review. Environ. Impact Assess. Rev. 1998, 18, 493-520.

2. Frame, B. Wicked, messy, and clumsy: Long-term frameworks for sustainability. Environ. Plann. C: Gov. Policy 2008, 26, 1113-1128.

3. White, S.S.; Ellis, C. Sustainability, the environment, and new urbanism: An assessment and agenda for research. J. Archit. Plan. Res. 2007, 24, 125-142.

4. Berke, P. Does sustainable development offer a new direction for planning? Challenges for the twenty-first century. J. Plan. Lit. 2002, 17, 21-36.

5. Azapagic, A.; Perdan, S. An integrated sustainability decision support framework. Part 2: Problem Analysis. Int. J. Sustain. Dev. World Ecol. 2005, 12, 112-131.

6. Priemus, H. How to make housing sustainable? The Dutch experience. Environ. Plann. B 2005, 32, 5-19.

7. Basiago, A. Economic, social, and environmental sustainability in development theory and urban planning practice. Environmentalist 1999, 19, 145-161.

8. Hodge, T. Towards a conceptual framework for assessing progress towards sustainability. Assessing progress towards sustainability. Soc. Indic. Res. 1997, 40, 5-98.

9. U.S. Green Building Council. Green Building by the Numbers 2009. Available online: http://www.usgbc.org/ShowFile.aspx?DocumentID=3340 (accessed on 10 August 2011).

10. Sustainable Sites Initiative (SSI). Guidelines and Performance Benchmarks-Draft 2008. Available online: http://www.sustainablesites.org/report/SSI_Guidelines_Draft_2008.pdf (accessed on 10 August, 2011).

11. Holowka, T. USGBC: LEED-Immediate Savings and Measurable Results; Environmental Design + Construction: Washington, DC, USA, 2007.

12. Haselbach, L. The Engineering Guide to LEED-New Construction; McGraw-Hill: New York, NY, USA, 2008.

13. Smalley-Bowen, T. The LEED Rating System's Effectiveness Rating System's Effectiveness is Dubious at Best. In EcoArchitecture; Fisanick, C., Ed.; Greenhaven Press: Farmington Hills, MI, USA, 2008. 
14. Healy, S. Science, technology, and future sustainability. Futures 1995, 27, 611-625.

15. Martens, P. Sustainability: Science or fiction. Sustain.: Sci. Pract. Policy 2001, 2, 1-5.

16. Brandon, P.; Lombardi, P. Evaluating Sustainable Development in the Built Environment; Blackwell Science: Oxford, UK, 2005.

17. Hughes, B.; Johnston, P. Sustainable futures: Policies for global development. Futures 2005, 37 , 813-831.

18. Newman, L. Change, uncertainty, and futures of sustainable development. Futures 2006, 38, 633-637.

19. Gibson, R.; Hassan, S.; Holtz, S.; Tansey, J.; Whitelaw, G. Sustainability Assessment: Criteria, Processes and Applications; Earthscan: Sterling, VA, USA and London, UK, 2005.

20. Mitchell, G. Problems and fundamentals of sustainable development indicators. Sustain.Dev. 1996, 4, 1-11.

21. Davidson, K.; Venning, J. Sustainability decision-making frameworks and the application of systems thinking: an urban context. Local Environ. 2011, 16, 213-228.

22. Munier, N. Methodology to select a set of urban sustainability indicators to measure the state of the city, and performance assessment. Ecol. Indic. 2011, 11, 1020-1026.

23. Parris, T.; Kates, R. Characterizing and measuring sustainable development. Annu. Rev. Environ. Resour. 2003, 28, 559-586.

24. Jankowski, P. Integrating geographic information systems and multiple criteria decision-making methods. Int. J. Geogr. Inf. Syst. 1995, 9, 251-273.

25. Graymore, M.; Wallis, A.; Richards, R. An index of regional sustainability: A GIS-based multiple criteria analysis decision support system for progressing sustainability. Ecol. Complex. 2009, 6, 453-462.

26. Malczewski, J. GIS and Multicriteria Decision Analysis; J. Wiley \& Sons: New York, NY, USA, 1999.

27. Malczewski, J. GIS-based land-use suitability analysis: A critical overview. Prog. Plan. 2004, 62, $3-65$.

28. Bishop, P.; Hines, A.; Collins, T. The current state of scenario development: An overview of techniques. Foresight 2007, 9, 5-25.

29. Bezold, C. Alternative futures for communities. Futures 1999, 31, 465-473.

30. Singh, R.; Murty, H.; Gupta, S.; Dikshit, A. An overview of sustainability assessment methodologies. Ecol. Indic. 2009, 9, 189-212.

31. Becket Open Space Planning Committee. Becket Open Space Plan. 2007. Available online: http://www.becket-ma.gov/Public_Documents/BecketMA_OpenRecPlan/OSRecPlan (accessed on 20 December 2011).

(C) 2012 by the authors; licensee MDPI, Basel, Switzerland. This article is an open access article distributed under the terms and conditions of the Creative Commons Attribution license (http://creativecommons.org/licenses/by/3.0/). 